\title{
LEUCOPLASIA DA MUCOSA BUCAL NA ANEMIA DE FANCONI APÓS O TRANSPLANTE DE CÉLULAS-TRONCO HEMATOPOIÉTICAS: RELATO DE CASO
}

Camila Pinheiro FURQUIM, Renata Lins Fuentes ARAUJO, Karine LYKO, Cassius Carvalho TORRESPEREIRA, Carmem BOMFIM

A anemia de Fanconi ( $\mathrm{AF}$ ) é uma doença genética rara que leva à falência progressiva da medula óssea. Para tratamento das alterações hematológicas indica-se transplante de células-tronco hematopoiéticas (TCTH). Uma complicação preocupante pós TCTH é o surgimento de neoplasias malignas associadas à doença do enxerto contra o hospedeiro (DECH). Neste relato enfatizaremos a importância do exame clínico na detecção de lesões com potencial de malignização na AF. Paciente masculino, 14 anos, com AF, submetido ao TCTH (não aparentado) há 5 anos, sem manifestações de DECH multisistêmica, sem uso de quaisquer medicamentos foi encaminhado para avaliação na disciplina de Estomatologia/UFPR. Ao exame clínico observaramse lesões leucoplásicas assintomáticas, evolução desconhecida, em palato duro $(6 \mathrm{~mm})$ e bordo de língua $(1 \mathrm{~cm})$. Pacientes com AF necessitam de observação sistemática da mucosa bucal para detecção do carcinoma espinocelular, pois inicialmente ele apresenta-se como uma lesão sutil, sendo difícil sua diferenciação com a DECH crônica. Foi agendada uma biopsia incisional, o paciente orientado a realizar inspeção bucal rotineira. Este relato reforça que a inspeção visual periódica configura-se como método prioritário na prevenção do câncer bucal em pacientes com AF pós TCTH, já que o risco de malignização torna-se maior na presença de $\mathrm{DECH}$ e com aumento do tempo pós-transplante.

Palavras-chave: Anemia de Fanconi; carcinoma espinocelular; rejeição de enxerto. 